\section{SECURING THE EVIDENCE BASE FOR PUBLIC HEALTH AND ACTING ON IT}

Among the readers of our journal this month will be both abusers and those who have been abused by people close to them. Throwing the spotlight on this difficult issue is one that people still have trouble with, and obtaining reliable data is still elusive. One of our research reports this month, on "Sexual assault among North Carolina women", and the linked editorial taking a more global perspective, try to do just that. If the lower limits of the estimates of women reporting physical violence from their male partners are anywhere near accurate $(20 \%-$ $50 \%)$, it is a shocking indictment of the way in which men are socialised around the world and of our unwillingness to take effective remedial action. We need more action-orientated work in this area, and we might begin by tackling these questions where we have some direct control and influences, in our own families and neighbourhoods, in health and public services, and in the universitiesblind spots to acting in our own backyard are a major part of the problem.

See pages 242,265

Work on stressors in the workplace continues to refine our understanding of job control and its effect on public health. We have a research report on the impact of employee control over working time on subjective health and sickness absence. Lamb and colleagues provide helpful information on the value of promoting health walks as a community measure, and Silventoinen and his colleague, from Finland, have captured a long term cohort effect on inequalities in health in the Nordic countries that may reflect the rumbling impact of the turmoil in Europe half a century ago.

See pages 246, 253

A warning by Suojanen, also from Finland, on the dangers of excessive fortification of food with calcium additives reminds us once again of the precautionary principle. And staying with the Scandinavians, quite a theme this month, the Inuit in Greenland were found to have lower blood pressures than their compatriots in Denmark although this effect was not found among the better educated, suggesting that the blood pressure of the Inuit, especially Inuit men, may be responsive to factors related to the Western way of life.

See pages 259, 279

Not from Scandinavia, but not far away, an examination of trends in childhood head injury mortality in Scotland between 1986 and 1995 found that an appalling total of 290 children died from head injury during this period. The good news is that the trend is downwards, but the social differences increased in the 10 to 14 year age group, with pedestrian accidents being the leading cause. The attrition of our infatuation with the motor car continues to impact on those with their lives ahead of them.

\section{See page 285}

An interesting finding from Germany is that, perhaps counter-intuitively, the use of acute hospital beds was found in a seven year cohort study not to increase as the population ages. This finding clearly has important implications for projections of future healthcare expenditure, but I suspect that it is strongly dependent on the availability of alternative forms of housing and medical and social care provision.

See page 289

Our Theory and Methods section this month includes contributions on developing risk estimation models for the psychosocial work environment, a comparison of hospital discharge records with death certificates, and a cancer survival model that, importantly, takes sociodemographic variations in "normal" mortality into account. See pages 294, 301, 309

More controversy in our letters this month—this time over milk and coronary heart disease mortality. Is it still true that if you have two dietary researchers in a room together, you inevitably have the basis for an argument?

See page 319

Readers are reminded of the facility for "rapid response" to papers published in the journal. Just log on to our web site at www.jech.com and click on the "eLetters" button when you have found the paper that interests you. Dynamic journals need dynamic readers.

\title{
APHORISM OF THE MONTH
} \section{Hospital beds}

Dofessor Bob Logan, when he was Professor of Medical Care at the London School of Hygiene and Tropical Medicine, used to say that:

"You can't grow potatoes in an empty bed." closely linked with another Logan Law, that:

"The number of beds you have is the number of beds you need."

I was reminded of this this month, reading the report from Germany that the use of acute hospital beds does not increase as the population ages. Presumably the system has other means of meeting needs.

John R Ashton, CBE 